\title{
Investigating the relationship between pollination strategies and the size-advantage model in zoophilous plants using the reproductive biology of Arum cylindraceum and other European Arum species as case studies
}

\author{
Natacha Revel • Nadir Alvarez • Marc Gibernau • \\ Anahí Espíndola
}

Received: 4 August 2011 / Accepted: 11 October 2011/Published online: 29 October 2011

(C) Springer Science+Business Media B.V. 2011

\begin{abstract}
The size-advantage model (SAM) explains the temporal variation of energetic investment on reproductive structures (i.e. male and female gametes and reproductive organs) in long-lived hermaphroditic plants and animals. It proposes that an increase in the resources available to an organism induces a higher relative investment on the most energetically costly sexual structures. In plants, pollination interactions are known to play an important role in the evolution of floral features. Because the SAM directly concerns flower characters, pollinators are expected to have a strong influence on the application of the model. This hypothesis, however, has never been tested. Here, we investigate whether the identity and diversity of pollinators can be used as a proxy to predict the application of the SAM in exclusive zoophilous plants. We present a new approach to unravel the dynamics of the model and test it on several widespread Arum (Araceae) species. By identifying the species composition, abundance and spatial
\end{abstract}

Handling editor: Jonathan Lundgren

Electronic supplementary material The online version of this article (doi:10.1007/s11829-011-9164-1) contains supplementary material, which is available to authorized users.

\section{N. Revel}

Laboratory of Evolutionary Entomology, Institute of Biology, University of Neuchâtel, Emile-Argand 11, 2009 Neuchâtel, Switzerland

N. Alvarez · A. Espíndola ( $₫)$

Department of Ecology and Evolution, University of Lausanne,

Biophore Building, 1015 Lausanne, Switzerland

e-mail: MariaAnahi.Espindola@unil.ch

M. Gibernau

CNRS-UMR 8172 Ecologie des Forêts de Guyane, BP 709,

97387 Kourou, France variation of arthropods trapped in inflorescences, we show that some species (i.e. A. cylindraceum and A. italicum) display a generalist reproductive strategy, relying on the exploitation of a low number of dipterans, in contrast to the pattern seen in the specialist A. maculatum (pollinated specifically by two fly species only). Based on the model presented here, the application of the SAM is predicted for the first two and not expected in the latter species, those predictions being further confirmed by allometric measures. We here demonstrate that while an increase in the female zone occurs in larger inflorescences of generalist species, this does not happen in species demonstrating specific pollinators. This is the first time that this theory is both proposed and empirically tested in zoophilous plants. Its overall biological importance is discussed through its application in other non-Arum systems.

Keywords Sex allocation - Plant-insect interactions . Araceae $\cdot$ Flower evolution $\cdot$ Reproductive strategy

\section{Introduction}

Energetic income is limited in all organisms, and natural selection optimises resource allocation strategies between growth/survival and reproduction according to physiological and environmental (biotic and abiotic) factors (Policansky 1982; Lloyd and Bawa 1984; Guillon et al. 2006). As a consequence, it has been proposed that in hermaphroditic and long-lived organisms, the reproductive energetic allocation varies with the size of the organism. In general, when the amount of available resources increases, the size of an organism tends to increase, which favours the relative increase in the number of the most costly sexual structures. This model, namely the size-advantage model 
(SAM), was first proposed (Ghiselin 1969) and tested (Warner 1988) in animals, but was later applied to dioecious and hermaphroditic plants (Lloyd and Bawa 1984), e.g., in species within the genera Acer L. (Sapindaceae) (Primack and McCall 1986), Arisaema Mart. (Araceae) (Vitt et al. 2003) and Arum L. (Araceae) (Méndez 2001).

According to the model, floral resource allocation, i.e. the quantity of energy invested by a plant in the production of female versus male sexual structures (Lloyd and Bawa 1984), depends on the energy available at a certain time: when only the amount of available resources increases, plants can become bigger and thus present larger inflorescences, which are predicted to harbour a higher proportion of female flowers (i.e. the most energetically costly sexual structure) than smaller inflorescences of the same species. Since its first application, the comprehensiveness of the SAM has been progressively enhanced by the inclusion of additional factors such as local sexual competition and differential gamete dispersion (Lloyd and Bawa 1984), wind-pollination syndromes (Burd and Allen 1988), plant geometry (Bickel and Freeman 1993), variation in environmental quality (Guillon et al. 2006) and mortality risks (Brooks and Iwasa 2010). However, even if pollination biology is known to strongly shape floral characters (Raven et al. 2005), few studies have tested its influence on the application of the SAM. A notable exception is the general study presented by Cruden (1977), largely criticised by Charnov (1982) some years later. The basis of this criticism relied on Cruden's assumption that male reproductive success was a function of seed-set only, indirectly suggesting that male gametes had no effect on the final fitness gain of the plant. As a result of this well-founded criticism, studies that considered the effect of pollination system on SAM became rare (Barrett et al. 1996). From a modelling approach, the lack of investigation on this topic might have also been a consequence of the complexity of some mathematical models developed to understand the SAM (Guillon et al. 2006).

Despite the criticism and the apparent complexity of the subject, we consider that some simple predictions may be proposed regarding the possible influence of pollinators on the investment towards a given gamete type. Historically, Lloyd and Bawa (1984) proposed that a gamete positivebias is expected for the gamete dispersing longer distances, since this would avoid intra-plant gamete competition. Here, we revisit this hypothesis from the point of view of pollinators. In an exclusively zoophilous plant, in which pollen is dispersed strictly by animals, pollen dispersion is directly related to pollinator efficiency, which is a function of both the number of pollinators visiting a flower, and of their individual capability to effectively cross-pollinate. In these plant types, if pollinators are scarce, present a low ability to cross-pollinate, or both, the probability of cross- pollination is expected to be low. In such circumstances, female gametes should be favoured in large plants, because pollen dispersion is expected to be low and intra-plant pollen competition expected to be high (Klinkhamer et al. 1997). In addition, by investing in female flowers, the number of pollinated ovules would quickly increase as soon as an eventual pollen-carrier visits the flower. In contrast, an investment in male gametes in such a situation would translate into a large male gamete loss. Alternatively, if pollinators are abundant, cross-pollination is efficient, or both, the probability of cross-pollination is expected to be high. In such a situation, it is likely that the pollen produced will present a high probability of reaching another flower, diminishing potential intra-plant pollen competition. Matching the SAM in such a context is expected to be counter-selected because the plant has the possibility to favour both its fruit set and male gamete dispersion (Chartier and Gibernau 2009).

While the number of pollinators visiting a plant is simple to quantify, the efficiency of pollination could be inferred from pollinator diversity (in terms of number of different taxa visiting a flower). This can be considered as a proxy of the level of specificity of a plant species' total pollination interaction (along a continuum between generalist and species-specific pollination, Ollerton et al. 2007) and thus indirectly represents the proportion of specific pollen that pollinators bring to the flower. It is important to mention here that the level of specificity of the interaction in this case is then considered to be happening at the pollinator species and not at the individual level (Chittka et al. 1999). From this perspective, a generalist pollinator species would carry mostly non-specific pollen, thus representing an inefficient crosser (Harder and Thomson 1989), while the opposite should be true for a specific pollinator. We would thus expect generalist flowers to apply the SAM, since male gamete losses are very likely to occur.

The overall probability of cross-pollination in a zoophilous plant appears then to be related both to the efficiency of pollinators (i.e. its visitation rate, constancy and capability to cross-pollinate) and to the nature of the interaction (i.e. specific or generalist). From this perspective, we expect that very efficient and specific pollinators would provide a high probability of cross-pollination, which would not favour the application of the SAM, because high rates of pollen dispersion and low intra-plant gamete competition are expected. Selection towards SAM expression should be an advantage, however, in the case of generalist and inefficient visits, since low rates of pollen dispersion and high intraplant gamete competition are expected. Predictions regarding the application of the SAM as a function of both pollinator diversity (i.e. different taxonomic groups and species) and efficiency (i.e. number of pollinators of each species/taxonomic group) are summarised in Fig. 1. It is 


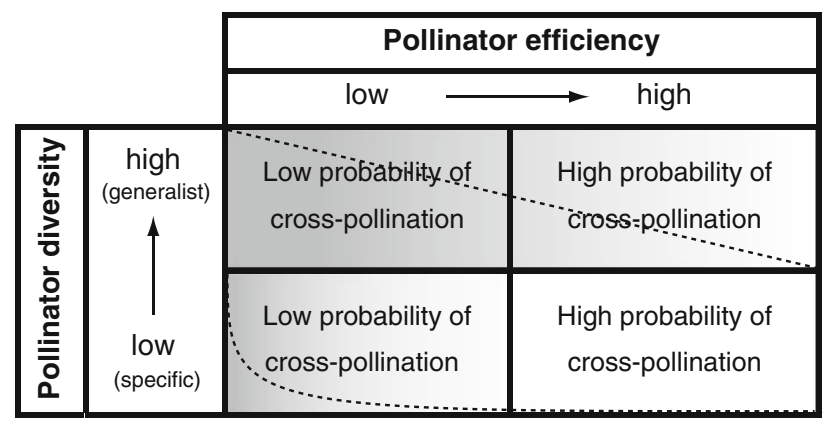

Fig. 1 Predictions of application of the size-advantage model (SAM), considering pollinator diversity and efficiency in zoophilous plants. Because factors are continuous, grey scales (dark high probability, white low probability) and dashed lines indicate the expected variation of the probability of application of the SAM. Note that in specific interactions, the application of the SAM is expected to be advantageous mainly at very low visitation rates (low net pollination efficiency), since specificity in plant-insect interactions is generally associated with highly efficient individual cross-pollination due to coevolutionary processes

important to note that the shape of the probability curve for the application of the SAM is expected to be different for cases in which specific or generalist pollinators are involved, meaning a faster decrease in intra-plant pollen competition in the case of specific visitors. This is expected because siring is more effective in the case of specialists, and thus, the visit of a reduced number of pollinators from few specific species would translate into a higher relative probability of receiving pollen from the "correct" species than if they were generalists.

Geophytic Araceae species are well suited to test hypotheses within the SAM framework since in this family, inflorescence and plant size are tightly related to reserves stored in the tuber (Méndez and Obeso 1993; Vitt et al. 2003) and increase as a function of plant age. For instance, it has been demonstrated that Arum italicum Mill. and A. idaeum Coust. \& Gand. do not produce any inflorescence until the tuber mass has reached a threshold weight, after which larger plants produce more inflorescences than smaller ones (Méndez and Obeso 1993). The simplest view of the SAM in Araceae predicts a trend towards feminisation in larger inflorescences, which has been demonstrated in several species within the family (e.g. Gibernau and Albre 2008; Lovett-Doust and Cavers 1982; Richardson and Clay 2001).

Among bulbous Araceae, the genus Arum is particularly suitable for testing hypotheses related to the effect of pollinator efficiency and diversity on the application of the SAM. The genus includes protogynous, thus generally selfinfertile species, which present similar ecologies and biologies (Boyce 1993) and express insect-pollination syndromes with different degrees of pollinator specificity
(Gibernau et al. 2004). The genus Arum comprises 28 species, most of them with a peri-Mediterranean distribution (Boyce 1993; Espíndola et al. 2010). As all members of the Araceae family, plants are characterised by singular floral structures, including a spadix harbouring flowers, surrounded by a spathe, a modified bract (Mayo et al. 1997). A special feature of the genus is that this basic floral structure is adapted to the attraction and trapping of pollinators (lure-and-trap antagonistic pollination). In all but two species (i.e. A. creticum Boiss. \& Heldr. and A. idaeum Coustur. \& Gand.), a spathe contraction takes place just above the fertile flowers, where sterile flowers transformed into hairs (i.e. staminodes) delimitate a closed floral chamber (Boyce 1993). Another remarkable feature of Arum species is their ability to produce heat and odour during anthesis in order to attract and temporarily capture potential pollinators (Gibernau et al. 2004; Urru et al. 2011). Probably because of the substantial amount of energy involved both in the characteristic floral structure and in heat and odour production, a trend towards specificity in pollinator attraction is generally detected (Gibernau 2003). However, there is strong variation in pollinator diversity levels across the different Arum species, and based on our hypothesis, we might expect that the application of the SAM is heterogeneous within the genus (see below). At one end of the continuum are species such as the specialist A. maculatum L., a widespread European species presenting high efficiency in attracting pollinators while showing a highly specific interaction with two species of the tribe Psychodini [i.e. Psychoda phalaenoides L. and Psycha grisescens Tonnoir (Diptera: Psychodidae); Espíndola et al. 2011]. At the other end are species such as the generalist $A$. italicum Mill.- -also widely distributed in Europe-whose efficiency in attracting pollinators is lower (a mean of 1.7 pollinators trapped per inflorescence, Albre and Gibernau 2008) and is visited by multiple arthropods from different families and orders (Albre et al. 2003). While the latter species matches the SAM (Albre and Gibernau 2008; Méndez 2001), the former does not (Chartier and Gibernau 2009). These two species therefore confirm predictions illustrated in Fig. 1: plants visited by efficient and specific pollinators should not follow the SAM, while those visited by rare and generalist pollinators should increase their fitness by following the model. It is, however, difficult to confirm this theory based on these two single cases. For this reason, we propose to further test our predictions by investigating another widely distributed European Arum species, A. cylindraceum Gasp. The choice of this species is based on its wide distribution, similar to that of the other currently well-known Arum species, thus decreasing possible effects of other untested external factors (e.g. environmental features, local adaptations) on the application of the SAM. 
Table 1 Descriptive statistics of allometric measures in inflorescences of Arum cylindraceum

\begin{tabular}{|c|c|c|c|}
\hline & & Mean & SE \\
\hline \multirow[t]{2}{*}{ Number of flowers } & Female & 38.92 & 1.67 \\
\hline & Male & 71.61 & 2.70 \\
\hline \multirow[t]{3}{*}{ Floral zone length $(\mathrm{cm})$} & Female & 0.92 & 0.028 \\
\hline & Male & 0.46 & 0.012 \\
\hline & Sterile & 1.44 & 0.039 \\
\hline \multirow[t]{2}{*}{ Total length $(\mathrm{cm})$ sex ratio ${ }^{a}$} & & 2.81 & 0.035 \\
\hline & & 0.65 & 0.011 \\
\hline
\end{tabular}

${ }^{a}$ From the base of the female zone to the highest staminode (not including the stipe and the appendix)

SE standard error

Arum cylindraceum is a recently rediscovered and redescribed species (Bedalov and Küpfer 2005; Fridlender 1999), whose ecology and biology have been little investigated. Its centre of distribution is Eastern Europe, being present from Spain and the Balkans to Poland and Denmark (Bedalov and Küpfer 2005). Until now, no studies have addressed the question of the identity of pollinators in this species.

In the present work, we investigate the pollination strategy of A. cylindraceum at the species level and use it as a third case study to test the consistency of our predictions on the SAM as a function of pollinator efficiency and diversity. In order to identify the level of specificity in the pollination interaction of A. cylindraceum and to get a large-scale overview of its geographical consistency, we study the species composition of arthropod visitors-and thus potential pollinators-throughout the distribution range of the plant. This allows us to evaluate both the type of pollinators visiting the species (i.e. specific vs. generalist) and the level of efficiency in pollination as a function of the number and identity of visitors attracted. Using these cues and applying the predictions presented above (see Fig. 1), we compare results in efficiency and diversity of pollinators with allometric measures taken on the inflorescences of the sampled plants and test the following expectations: (1) a combination of high insect diversity (e.g. more than four taxa) and low number of visitors (e.g. less than 15) is expected to be found in plants conforming to the SAM, because the probability of cross-pollination is expected to be low (as in A. italicum); (2) a low insect diversity (e.g. up to four taxa) combined with a high number of visitors (e.g. more than 15) should be related with the non-conformity to the SAM, since the probability of cross-pollination is expected to be high (as in A. maculatum); (3) a combination of low insect diversity and number is expected in plants matching the SAM (low net probability of cross-pollination, especially if the number of pollinators is extremely low); (4) a combination of high insect diversity and number is expected to be present in plants that do not match the SAM (high net probabilities of cross-pollination).

\section{Materials and methods}

Sampling and pollinator identification

Twenty-four Arum cylindraceum populations were sampled from April to May 2008 in central and southern Europe and the Balkans, covering thus most of its distribution range (Bedalov and Küpfer 2005). While other Arum species flower from February to June (Boyce 1993), A. cylindraceum is known to flower only once and relatively early in the season (Fridlender 1999). The timing of our sampling thus allowed us covering the entire flowering period of all visited regions. Considering the small average population sizes (less than 80 plants) and highly aggregated intra-population distribution, we excluded the effect that clonal reproduction (a feature known for the genus, Boyce 1993) could have on our results by restricting the number and intra-population distribution of sampled individuals. Moreover, because this study addresses the reproductive strategy displayed by the species and not necessarily by each population, we favoured a sampling of some plants from different geographic regions, over many of only some counted locations. Because of these reasons, up to six (and minimum two, in two cases) floral chambers per population were selected from plants separated by a distance of more than five metres from their closest sampled neighbour. Once floral chambers were collected, they were labelled and independently preserved in $70 \%$ ethanol. A plant voucher was collected at each location, and geographic coordinates were registered using a GPS Etrex Garmin.

Arthropods were identified to the ordinal level using the identifications keys provided by Freude et al. (1964). Diptera were identified to the species level following different approaches. Because of the lack of updated identification keys for several families of Diptera, European experts (see acknowledgments section) were consulted for the identification of samples belonging to this group. An exception is the Psychodidae family, for which keys are actually available (Ježek 1990; Withers 1988). Occurrences of each visiting species/genus/family were recorded and numbers per floral chamber, per population and in total were calculated, as well as the sex ratio of the most abundant visitors.

Because the identity and the number of pollinators have been shown to vary geographically in other Arum species (Espíndola et al. 2011), we tested for an eventual spatial structure by analysing the geographic visitor composition using ArcMap 9.3 (ESRI, Redlands CA, USA). 
Allometric measures

A maximum of three inflorescences per population $(n=39)$ were selected to perform allometric measures (lengths of the spadix, female and male zones). Numbers of male and female flowers were counted and floral sex ratios calculated. The floral sex ratio was inferred as: number of male flowers/(number of male flowers + number of female flowers), where 1 represents a complete male and 0 indicates a complete female. Following the approach established by Chartier and Gibernau (2009), regions of the inflorescence were divided into fertile male and female zones, and their lengths were measured with a digital calliper (TESA, model CCMA-M). Because the addition of fertile and sterile zones is linearly correlated with the total size of the inflorescence (M. Gibernau, pers. obs.), we measured the length from the base of the female fertile zone to the last upper staminodes and used this value as a proxy of the total spadix length, a value correlated with the total plant size, and thus with available resources (Albre et al. 2003).

Descriptive statistics and correlations (linear regressions for lengths; logistic regressions for counts) were calculated based on the recorded data, applying the functions $l m$ and $\mathrm{glm}$ implemented in R 2.9.0 (R Development Core Team 2009). Because the present study was focused on general floral patterns intrinsic to the species, all analyses were performed considering all populations together and did not investigate inter-populational variation.

\section{Testing predictions}

In order to test predictions made by our model (Fig. 1), we applied a comparative method. Based on the data obtained from insect identification, we inferred diversity and efficiency of pollinators in each population. Diversity was inferred following the approach applied by Ollerton et al. (2007), which defines it as a measure of the number of interacting species. Efficiency was estimated by considering the total number and the constancy in the composition of visitors from a spatial point of view, since it is unlikely that a group of rare, diverse and inconstant visitors presents high overall pollination efficiency, while the opposite is likely to be true for abundant and specific visitors.

The fit of the predictive model was thus tested by first using these indirect measures of diversity and efficiency to identify the theoretical expectations corresponding to the observed diversity-efficiency combination. The prediction made by the model was then compared to the empirical results obtained from the allometric survey. Finally, congruence between the empirical allometric results and the theoretical expectations was used to indicate the level of accuracy of our model.

\section{Results}

Visitors' diversity and distribution

Twenty-four populations were sampled (Supplementary Material 1) and 80 floral chambers collected, containing 252 arthropods distributed in half of the populations (12 populations did not harbour any visitors). This represented a mean of $3.50(\mathrm{SE}=0.57)$ and $12.75(\mathrm{SE}=3.64)$ arthropods per floral chamber and per population, respectively.

The collected visitors (Fig. 2) were restricted to arthropods and represented by the classes Insecta (67.9\%), Arachnida (Acarina, 18.2\%), Diplura (7.1\%) and Collembola (6.7\%). The two most frequent orders were Diptera (65.5\%) and Coleoptera (28.1\%). The order Diptera comprised families Psychodidae (57.1\%), Ceratopogonidae (14.3\%), Sphaeroceridae (10.7\%), Sciaridae (7.1\%), Cecidomyiidae (3.6\%), Chironomidae (3.6\%), Mycetophilidae (2.7\%) and Phoridae (0.9\%).

Regarding the diversity found in each family of Diptera, our results show that Psychodids were represented by a large majority of Psycha grisescens (82.8\%, mainly males) and lower proportions of females of Psychoda phalaenoides (14.1\%) and P. albipennis Zett. (3.1\%). Ceratopogonids were identified as Culicoides obsoletus Meigen (94\%) and Atrichopogon oedemerarum Stora (6\%). Species of Sphaeroceridae were Spelobia clunipes Meigen (58.3\%), Coproica ferruginata Stenhammar (33.3\%) and C. vagans Haliday (8.4\%). Concerning Sciarids, we could only identify them to the two genera Bradysia Winnertz (63\%) and Phytosciara Frey (25\%). Samples of the remaining families were very scarce (less than $11 \%$ in total): taxa were Smittia leucopogon Meigen (Chironomidae), genera Azana Walker and Boletina Staeger. (Mycetophilidae) and subfamilies Orthocladiinae (Chironomidae), Lestremiinae and Cecidomyiinae (Cecidomyiidae). No sub-familial identification was possible on the unique Phorid sample.

The spatial distribution of these groups was not geographically structured in terms of composition (Fig. 3a) nor of number of visitors trapped (Fig. 3b).

\section{Allometric measures}

There was a positive correlation between the length of each floral zone (i.e. male, female and sterile, Table 1) and the total inflorescence length (Fig. 4a). The length-increase of the sterile floral zone was the highest (slope $=0.562$ ), followed by female (slope $=0.334$ ) and male (slope $=$ 0.103 ) zones. Each factor significantly increased the adjustment of the general linear model indicating that the three slopes are different $(P<0.001$ in all pairwise tests, $\left.R^{2}=0.946, F=379.2\right)$.

Another positive correlation was observed between the number of fertile flowers and the total inflorescence length 




Fig. 2 Visitor composition of Arum cylindraceum floral chambers in 12 populations at three taxonomic levels: Arthropod classes, Insecta orders, Diptera families. Total numbers of specimens are indicated below each group

(Fig. 4b). The slope was higher for the number of female (slope $=0.462)$ than male (slope $=0.225)$ flowers, and both slopes were significantly different $\left(P=0.015, z_{(\mathrm{fem})}=\right.$ 5.781, $\left.z_{(\text {male })}=-2.425\right)$.

The inflorescence floral sex ratio was negatively correlated (slope $=-0.063, R^{2}=0.094, F=4.626, \quad P=$ 0.039) with the total inflorescence length (Fig. 4c), indicating a significant feminisation of the inflorescence with an increase in the total size.

There was no significant correlation between the number of trapped insects and the total length of the inflorescence $(P>0.05$; Fig. 4d). This result was consistent even when samples containing no insects were excluded (data not shown) and despite the fact that mean total lengths were significantly different between those flowers containing visitors and those not $(F=4.992$; df $=1 ; P=0.032)$.

Correlations showed no population structure (data not shown), indicating that the observed patterns are intrinsic to the species and not to a specific region.

\section{Interaction between SAM and visitor composition}

When connecting results obtained from the visitor composition survey and the allometric measures, our results showed that $A$. cylindraceum presents a visitor pattern defined by high visitor diversities (Fig. 2), low visitor numbers and highly variable visitor compositions throughout the sampled area (low expected efficiency,
Fig. 3). In our model, this corresponds to the combination "high diversity-low efficiency", associated with the application of the SAM (Fig. 1).

The survey on the variation of reproductive allocation indicates that the plant modifies the proportion of one or the other flower type as a function of the available resources (Fig. $4 \mathrm{a}-\mathrm{c}$ ), indicating that the SAM is, as predicted, applied in A. cylindraceum.

\section{Discussion}

The diversity and efficiency of $A$. cylindraceum visitors

Our results show that, in comparison to other Arum species (A. italicum: Albre et al. 2003; A. maculatum: Espíndola et al. 2011), visitors of A. cylindraceum are scarce (3.5 per floral chamber on average, and completely absent in half of the populations) and highly diverse, comprising species from several insect groups. Because the plant is not able to be self-fertilised in the European continent (Chouteau et al. 2008; Fridlender 1999), such a low number of trapped insects was not expected. Since several species within the genus can reproduce by forming bulbs in a vegetative manner (Boyce 1993), it is likely that A. cylindraceum can reproduce by clonal means (Fridlender 1999) and that cross-pollination may rarely happen. However, during our sampling trips, we frequently found A. cylindraceum plants displaying fruits (A. Espíndola, pers. obs.). Another explanation for such a low number of sampled insects could be that the trapping system (i.e. the number and length of staminodes of A. cylindraceum) is not highly efficient in this species, which would release arthropods quickly after they have been trapped in the floral chamber. This would imply that this species is effectively visited by more arthropods than those found in the present study. Such a non-optimal strategy would require little energetic investment in terms of odour (e.g. fewer specific volatiles), heat and morphological features (e.g. length of staminodes). Another explanation could be that, as shown by Lack and Diaz in A. maculatum (1991), one or several insects carrying specific pollen is able to pollinate all female flowers, meaning that even when only rarely visited, plants can produce enough seeds to compensate the energetic investment made in reproductive structures. Long-term observation and sampling of all insects visiting the flowers during the whole anthesis would allow testing these ideas. Additionally, investigating the variation of pollen viability through time would also shed light on the temporal range during which pollen carry-over needs to happen and would provide indirect information on the natural dynamics of pollination. Also, genetic surveys in this species would help identify the level of vegetative and 
Fig. 3 Visitor composition in sampled populations. a Among Arthropod orders; b among Diptera families. Pie sizes in $\mathbf{b}$ are proportional to numbers of trapped insects (the scale is referred in the legend)

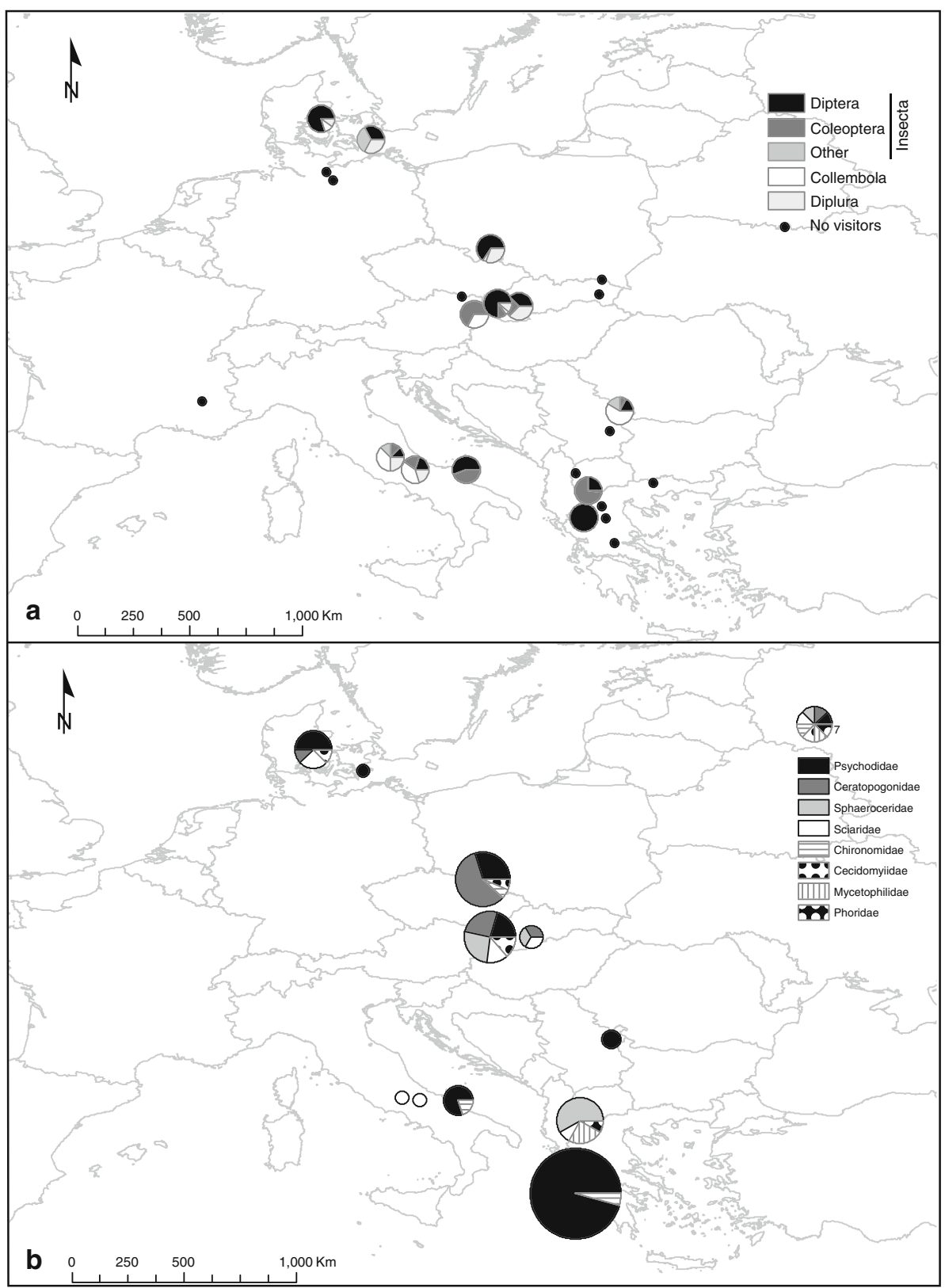

sexual reproduction, providing further data on the effective reproductive biology of the species.

Despite showing a low total number of visitors, our results still reveal a high diversity of insects and especially of Diptera (Fig. 2), as shown for some other Arum species (Gibernau et al. 2004). All dipteran families recorded here (with the exception of the three least abundant ones, i.e. Cecidomyiidae, Mycetophilidae and Phoridae) have been previously identified as visitors and thus potential pollinators of several other species within the Arum genus, as for example, A. dioscoridis and A. orientale (for a review, see Gibernau et al. 2004). Moreover, their simultaneous occurrence was also recorded in the floral chambers of A. italicum, where they were confirmed as effective pollinators (Albre et al. 2003). It is thus likely that insects trapped in the present study are reliable pollinators of A. cylindraceum.

Contrasting with a recent study on A. maculatum (Espíndola et al. 2011), the spatial distribution of visitors' composition does not show any specific geographic pattern (Fig. 3), indicating that the pollination strategy applied by the plant is intrinsic to the species and is not a result of any regional adaptation. Consequently, the plant appears as a widespread generalist, with a low level of efficiency in pollinator attraction across its entire distribution range. 



Fig. 4 Allometric measures of A. cylindraceum inflorescences. a Length of each floral region (male, female, sterile) as a function of the total inflorescence length: male (filled black circles; $\mathrm{T}_{\text {slope }}=7.225$, slope $\left.=0.103, P<0.001\right)$; female $($ empty circles; $\mathrm{T}_{\text {slope }}=3.695$, slope $\left.=0.334, P<0.001\right)$; sterile (filled grey circles; $\mathrm{T}_{\text {slope }}=10.722$, slope $\left.=0.562, P<0.001\right)$. b Number of female (empty circles, $Z=5.781$, slope $=0.462, P<0.001$ ) and male (filled circles, $Z=-2.425$, slope $=0.225, P<0.001$ ) flowers as a function

\section{Arum cylindraceum in the SAM perspective}

Because of its low efficiency and generalist behaviour, $A$. cylindraceum should be expected to conform to the SAM (Fig. 1). This prediction is confirmed by our results on the variation in the resource allocation applied by the plant (Fig. 4): there is a growing investment towards female function as inflorescence size becomes larger. The enlargement of the female floral zone is mostly due to an increase in the number of female flowers (Fig. 4b), indicating that not only the size but also the number of female flowers increases in larger plants. In agreement with the similar pattern found in A. italicum (Albre and Gibernau 2008), the mean floral sex ratio of the plant is biased towards the male function, but significantly feminises when the inflorescence size increases (Fig. 4c). This trend holds even if both flower types rise in numbers (Fig. 4b). These results fit predictions done by our simple SAM-pollinator model and thus provide further support to its general consistency in the case of zoophilous plants.
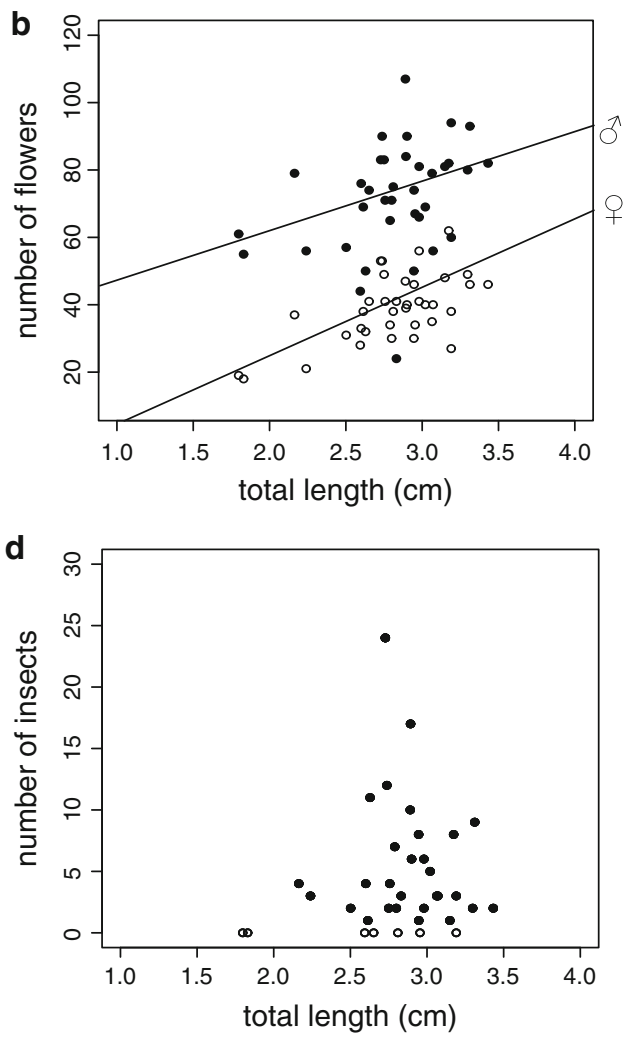

of total inflorescence length. c Floral ratio as a function of total inflorescence length $(T=-2.151$, slope $=-0.063, P=0.039)$. d Number of insects trapped as a function of total inflorescence length $(Z=2.819, P>0.05$; filled circles: inflorescences containing visitors; empty circles: inflorescences not containing visitors). The total inflorescence length is calculated from the basis of the female zone up to the highest staminode (not including the stipe and the appendix)

In Arum, it has been demonstrated that increase in plant size is associated with an enlargement of the organ involved in heat and odour production (Gibernau and Albre 2008) and a subsequent rise in pollinator attraction (Méndez and Obeso 1992). Experimentally, it has been moreover demonstrated that an increase in the flower size can also help attract pollinators in a more efficient way (Chittka et al. 2001). Our analyses, however, show that in A. cylindraceum, the increase in inflorescence size is not correlated with an increase in attractiveness (Fig. 4d). Moreover, this result corroborates our view of the interaction between A. cylindraceum and its associated pollinators as a low-efficiency pollination system.

We did not find evidence for any geographic structure in either the composition of insects or the floral characters (samples from the same locations were randomly distributed in the scatterplots; Fig. 4). Points from all locations were clearly distributed along a unique and continuous regression line, a result incompatible with local specialisations. This represents a further indication that the relationship between 
bulb size and floral allocation is intrinsic to the species and is not a result of any local adaptation. A final confirmation of this link would, however, require measuring bulb weights and floral allocations both at local and regional scales. Additionally, genetic surveys would help quantifying diversity in the populations.

\section{Pollination strategies and the SAM}

The combination of pollinator composition and plant allometric measures confirmed our expectations in the long-lived zoophilous species studied here, further supporting our initial hypothesis. This is the first time to our knowledge that this theory is both explicitly proposed and tested in an empirical pollination system.

It is important to note that our predictions in Araceae might also apply to other plant groups, for example, species of the genus Trillium L. (Melanthiaceae). In this group, low pollinator visitation and specificity with application of the SAM have been also registered (Wright and Barrett 1999), a case similar to that observed in A. cylindraceum and A. italicum. Moreover, the model also appears to predict the development of mono- or dioecy under different pollinator conditions: our results and our model correspond well to data gathered from the Australian genus Wurmbea (Barrett 1992), which showed that gynodioecy is expected to be favoured when pollinators are unreliable; this is a situation similar to the one proposed by our model in the case of rare and inefficient pollinators.

Finally, in order to expand the understanding of the dynamics of the SAM as a function of pollinator diversity and efficiency, it is necessary to analyse a wider number of plant-insect systems taking into account not only the variation in sex-resource allocation but also in pollinator diversity. In this context, the family Araceae is particularly suitable because biological (e.g. long-lived plants) and ecological characters (e.g. generalised zoophily) shared by its species greatly simplify the understanding of SAMrelated floral allocation responses. Moreover, the application and development of dynamic mathematical models in the SAM/pollinator context could provide important information on the expected shapes of probability curves proposed by our predictions and would thus help deepen our understanding of those factors driving the variation in investment in floral allocation.

Acknowledgments The authors are thankful to Dr. Kącki, Dr. Dajdok (University of Wrocław, Poland), Dr. Triponez and Prof. Küpfer (University of Neuchâtel, Switzerland) for their invaluable technical assistance during field work. They also thank Dr. Haenni, Dr. Rulik, Dr. Lods-Crozet, Mr. Chandler, Dr. Rohácek, Dr. Skuhravà and Dr. Szadziewski for their indispensable help during insect identification, and J. Litman for correcting the English. We thank two anonymous reviewers and the Editor for their constructive comments and suggestions. The present study was funded by the Swiss National Science Foundation (Project No. 3100A0-116778 awarded to N.A), the Matthey-Wütrich Grant of the University of Neuchâtel awarded to N.R. and the Travel Grant of the Swiss Academy of Sciences SCNAT + awarded to A.E. N.A. is currently funded by a Swiss National Science Foundation Ambizione fellowship (PZ00P3 126624).

\section{References}

Albre J, Gibernau M (2008) Reproductive biology of Arum italicum (Araceae) in the south of France. Bot J Linn Soc 156(1):43-49

Albre J, Quilichini A, Gibernau M (2003) Pollination ecology of Arum italicum (Araceae). Bot J Linn Soc 141(2):205-214

Barrett SCH (1992) Gender variation and the evolution of dioecy in Wurmbea dioica (Liliaceae). J Evol Biol 5(3):423-444

Barrett SCH, Harder LD, Worley AC (1996) The comparative biology of pollination and mating in flowering plants. Philos Trans R Soc Lond Ser B Biol Sci 351(1345):1271-1280

Bedalov M, Küpfer P (2005) Studies on the genus Arum (Araceae). Bull de la société Neuchâteloise des Sci Naturelles 128:43-70

Bickel AM, Freeman DC (1993) Effects of pollen vector and plant geometry on floral sex ratio in monoecious plants. Am Midl Nat 130:239-247

Boyce PC (1993) The genus Arum. The royal botanical gardens. Kew, London

Brooks M, Iwasa Y (2010) Size-dependent sex change can be the ESS without any size advantage of reproduction when mortality is size-dependent. Theor Popul Biol 78(3):183-191. doi:10.1016/j. tpb.2010.07.001

Burd M, Allen TFH (1988) Sexual allocation strategy in windpollinated plants. Evolution 42(2):403-407

Charnov EL (1982) The theory of sex allocation. Monographs in population biology, vol 18. Princeton University Press, Princeton

Chartier M, Gibernau M (2009) Size variations of flowering characters in Arum maculatum (Araceae). Aroideana 32:153-158

Chittka L, Thomson JD, Waser NM (1999) Flower constancy, insect psychology, and plant evolution. Naturwissenschaften 86(8): 361-377

Chittka L, Spaethe J, Tautz J (2001) Visual constraints in foraging bumblebees: flower size and color affect search time and flight behavior. Proc Natl Acad Sci USA 98(7):3898-3903

Chouteau M, Gibernau M, Barabé D (2008) Relationships between floral characters, pollination mechanisms, life forms, and habitats in Araceae. Bot J Linn Soc 156:29-42

Cruden RW (1977) Pollen-ovule ratios: a conservative indicator of breeding systems in flowering plants. Evolution 31(1):32-46

Espíndola A, Buerki S, Küpfer P, Bedalov M, Alvarez N (2010) New insights into the phylogeny and biogeography of Arum L. (Araceae): unravelling its evolutionary history. Bot J Linn Soc 163:14-32

Espíndola A, Pellissier L, Alvarez N (2011) Variation in the proportion of flower visitors of Arum maculatum across its distributional range in relation with community-based climatic niche analysis. OIKOS 120(5):728-734

Freude H, Harde KW, Lohse GA (1964) Die Käfer Mitteleuropas. Goecke \& Evers, Krefeld

Fridlender A (1999) Observations sur la biologie de l'Arum cylindraceum (Gasp.) Araceae en Corse. Acta Bot Gallica 146(4):297-309

Ghiselin MT (1969) The evolution of hermaphroditism among animals. Q Rev Biol 44(2):189-208 
Gibernau M (2003) Pollinators and visitors of Aroid inflorescences. Aroideana 26(11):73-91

Gibernau M, Albre J (2008) Size variations of flowering characters in Arum italicum (Araceae). Aroideana 31:101-106

Gibernau M, Macquart D, Przetak G (2004) Pollination in the genus Arum-a review. Aroideana 27:148-166

Guillon JM, Julliard R, Leturque H (2006) Evolution of habitatdependent sex allocation in plants: superficially similar to, but intrinsically different from animals. J Evol Biol 19(2):500-512. doi:10.1111/j.1420-9101.2005.01012.x

Harder LD, Thomson JD (1989) Evolutionary options for maximizing pollen dispersal of animal-pollinated plants. Am Nat 133(3): 323-344

Ježek J (1990) Redescriptions of nine common palaearctic and holarctic species of Psychodini End. (Diptera: Psychodidae). Acta Entomologica Musei Nationalis Pragae 43:33-83

Klinkhamer PGL, deJong TJ, Metz H (1997) Sex and size in cosexual plants. Trends Ecol Evol 12(7):260-265

Lack AJ, Diaz A (1991) The pollination of Arum maculatum L.-a historical review and new observations. Watsonia 18:333-342

Lloyd DG, Bawa KS (1984) Modification of the gender of seed plants in varying conditions. Evol Biol 17:255-338

Lovett-Doust J, Cavers PB (1982) Ressource allocation and gender in the green dragon Arisaema dracontinum (Araceae). Am Midl Nat 108:144-148

Mayo SJ, Bogner J, Boyce PC (1997) The genera of Araceae. Royal Botanical Gardens. Kew, London

Méndez M (2001) Sexual mass allocation in species with inflorescences as pollination units: a comparison between Arum italicum and Arisaema (Araceae). Am J Bot 88(10):1781-1785

Méndez M, Obeso JR (1992) Influencia del osmóforo en la producción de infructescencias en Arum italicum Miller (Araceae). Anales del jardín Botánico de Madrid 50:229-237
Méndez M, Obeso JR (1993) Size-dependent reproductive and vegetative allocation in Arum italicum (Araceae). Can J Bot 71:309-314

Ollerton J, Killick A, Lamborn E, Watts S, Whiston M (2007) Multiple meanings and modes: on the many ways to be a generalist flower. Taxon 56(3):1-12

Policansky D (1982) Sex change in plants and animals. Annu Rev Ecol Syts 13:471-495

Primack RB, McCall C (1986) Gender variation in a red maple population (Acer rubrum; Aceraceae): a seven-year study of a "Polygamodioecious" species. Am J Bot 73(9):1239-1248

Raven PH, Evert RF, Eichhorn SE (2005) Biology of plants, 7th edn. W.H. Freeman, New York

R Development Core Team (2009) R: a language and environment for statistical computing. R Foundation for Statistical Computing. Vienna, Austria

Richardson CR, Clay K (2001) Sex-ratio variation among Arisaema species with different patterns of gender diphasy. Plant Species Biol 16:139-149

Urru I, Stensmyr MC, Hansson BS (2011) Pollination by brood-site deception. Phytochemistry 72(13):1655-1666. doi:10.1016/j. phytochem.2011.02.014

Vitt P, Holsinger KE, Jones CS (2003) Local differentiation and plasticity in size and sex expression in Jack-in-the-pulpit, Arisaema triphyllum (Araceae). Am J Bot 90(12):1729-1735

Warner RR (1988) Sex change in fishes: hypotheses, evidence, and objections. Environ Biol Fishes 22(2):81-91

Withers P (1988) Moth flies diptera: psychodidae. Dipter Dig 4:1-83

Wright SI, Barrett SCH (1999) Size-dependent gender modification in a hermaphroditic perennial herb. Proc R Soc Lond B 266: 225-232 